\title{
Development of gear dynamic performance testing machine
}

\author{
Ke Li, Bo Yu* (D), Zhaoyao Shi, Zanhui Shu, and Rui Li \\ Beijing Engineering Research Center of Precision Measurement Technology and Instruments, Faculty of Materials \\ and Manufacturing, Beijing University of Technology, Beijing 100124, China
}

Received: 16 April 2021 / Accepted: 8 July 2021

\begin{abstract}
With the development of gears towards high temperature, high pressure, high speed and high stress, gear measurement, in which only the static geometric accuracy is considered, is unable to meet the current application requirements. While, the low precision and single function gear tester constrains the measurement of gear dynamic performance. For the resolution of this problem, based on the principle of gear system dynamics and several precision mechanical design techniques, a gear dynamic testing machine has been developed, providing new instruments for gear testing. On the basis of research of the principle of dynamic performance test, the primary measurement items of the testing machine have been determined. The measuring principles of each item and the driving and loading form of the testing machine have been examined. The measurement and control system of the testing machine and its corresponding software have been developed. The instrument can not only obtain the static precision index of the gear, but also obtain the dynamic performance index of the gear in variable working conditions. According to the actual test, the uncertainty of instrument is $3.8 \mu \mathrm{m}$ and the external disturbance caused by the shaft vibration is less than $0.6 \mu \mathrm{m}$, which can meet the $5-6$ grade precision gear testing requirement.
\end{abstract}

Keywords: Gear / transmission error / gear test / gear dynamics / gear vibration and noise

\section{Introduction}

The advantages of gear transmission are accurate driving, range of application, high bearing capacity, long life, high reliability, high transmission efficiency, compact structure and much more. Gear transmission is the most widely used of all mechanical transmission parts, which are essential to manufacturing equipment. It has a wide range of applications in various industries [1-3].

The Gear measurement technology has been developed for over 100 years. It can be classified into three categories: gear single geometric error measurement, gear comprehensive measurement and gear integrated error measurement [4]. These measurement techniques mainly focus on the measurement of geometric accuracy of gears, which belongs to the static performance measurement of gears. However, the modern industrial production takes the development in the direction of high precision, high speed and multiplefunctions, so only inspecting the geometric accuracy of the gear cannot meet the requirements of gears in the conditions of high temperature, high pressure, and high speed and high stress [5]. In particular, the current requirements on gear noise level are becoming stricter.

\footnotetext{
* Corresponding author: yubo@bjut.edu.cn
}

The test of gear static geometric precision cannot reach the increasing low noise requirement [6,7]. In general, the geometrical errors of the gears are intertwined with each other and interact with the operating conditions of the gears [8-10]. Therefore, it is necessary to predict the dynamic performance of gear during the design and manufacture, and the dynamic performance of gear can be detected before use.

Eventually the working speed of the gear transmission system will be higher, and the vibration and noise of gear transmission system will be more optimal. Pairing of involute cylindrical gears is the most convenient way to solve the reasonable use of large amounts of product gears. It is also an effective way to control gear vibration and noise in order to improve gear transmission quality [11,12]. At present, some gearbox manufacturers in Japan use gears after appropriate matching, and the comprehensive evaluation of the gear design and processing is adopted by detecting the effect of matching. Some gear manufacturers in the China have similar approaches [13,14]. Therefore, there is an urgent need for an instrument to test the dynamic performance of gear pairs before they are assembled in a gearbox [15-17].

Gear testing not only tests the conventional gear static strength, gear tooth bending fatigue strength, tooth surface wear and gear bonding test, but also contains gear parameters 


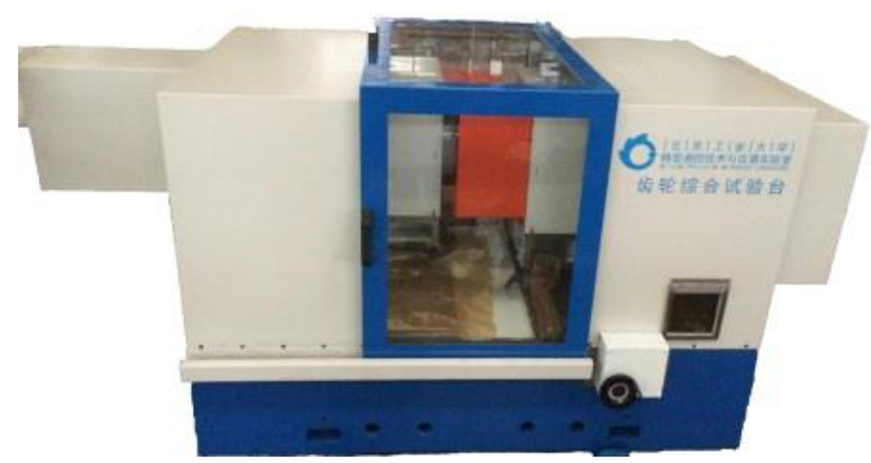

Fig. 1. Gear dynamic performance testing machine.

and other performance tests, such as gear efficiency, gear lubrication, gear dynamic load, gear noise, gear tooth load distribution, tooth surface and gear body temperature, and much more $[18,19]$. With different purposes, requirements and methods of the test, there are many different forms of gear testing equipment. Their loading methods, operating methods and structural patterns are often very different. These test equipment are generally designed for specific test purposes or meeting a certain requirement, and the accuracy of some equipment is relatively low.

In order to solve the problem of the dynamic performance measurement of the parallel shaft gears, a gear dynamic testing machine which can satisfy the static transmission error measurement and the gear dynamic performance test has been developed according to the gear dynamics principle, as shown in Figure 1. The test results show that the instrument can meet the requirements of dynamic performance testing of 5-6 grade precision gears.

\section{Test principle}

Gear dynamic excitation is affected not only by the structure, geometry and error of the gear itself, but also by other components of the system [20].

Since the direction of calculating the transmission error is along the meshing line, equation (1) mainly highlights the torsion vibration in the meshing line direction by using 1-DOF model. The cylindrical gear system can be simplified as the torsional vibration system of the gear pair without considering the elastic deformation of the drive shaft, supporting bearings, box and so on. The dynamic model is shown in Figure 2.

According to the theory of mechanical dynamics and mechanical vibration, the torsional vibration equation of a pair of gear pair is as follows:

$$
M \frac{d^{2} x}{d t^{2}}+c \frac{d x}{d t}+k x=W_{0}+W_{d}
$$

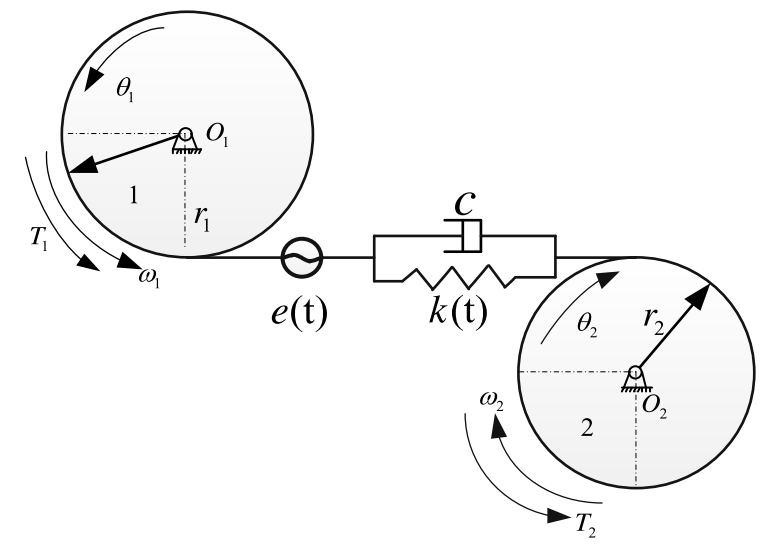

Fig. 2. Torsional vibration model of gear pair.

In which,

$$
\begin{gathered}
x=r_{1} \theta_{1}-r_{2} \theta_{2} \\
M=\frac{I_{1} I_{2}}{I_{1} r_{2}^{2}+I_{2} r_{1}^{2}} \\
W_{0}=\frac{T_{1}}{r_{1}}=\frac{T_{2}}{r_{2}} \\
W_{d}=k_{1} e_{1}+k_{2} e_{2}+c_{1} \frac{d e_{1}}{d t}+c_{2} \frac{d e_{2}}{d t} .
\end{gathered}
$$

$\theta_{i}(i=1,2)$ are torsional vibration angular displacement of the drive gear and the driven gear. $I_{i}(i=1,2)$ are rotary inertias of the driving and driven gears. $r_{i}(i=1,2)$ are base radiuses of the driving and driven gears. $k_{i}(i=1,2)$ is gear composite meshing stiffness of the $i$ th gear tooth pair. $c_{i}(i=1,2)$ is the damper coefficient of the $i$ th gear tooth pair. $k(t)$ is the gear pair composite meshing stiffness. $c$ is the gear pair meshing stiffness damper. $e_{i}(i=1,2)$ is the $i$ th gear tooth pair error. $T_{i}(i=1,2)$ are the external torques loaded on the driving and driven gears. So, the static transmission error can be derived from equation (1) by omitting the dynamic items (inertial force items and damping force items), which is shown as equation (2).

$$
x_{s}=\frac{W_{0}}{k(t)}+\frac{\left(k_{1} e_{1}+k_{2} e_{2}\right)}{k(t)}
$$

And then, the dynamic transmission error $x_{d}$ can be expressed as equation (3).

$$
x_{d}=\frac{W_{0}}{k(t)}+\frac{\left(k_{1} e_{1}+k_{2} e_{2}\right)}{k(t)}-\frac{c \dot{x}}{k(t)}+\frac{\left(c_{1} e_{1}+c_{2} e_{2}\right)}{k(t)}
$$

When testing the dynamic performance of the gear pair, it is necessary to know exactly the external load moment applied to the gear. When testing the static transmission error and the dynamic transmission error of the gear pair, it is essential to accurately know the rotation angles of the driving and driven gear. 


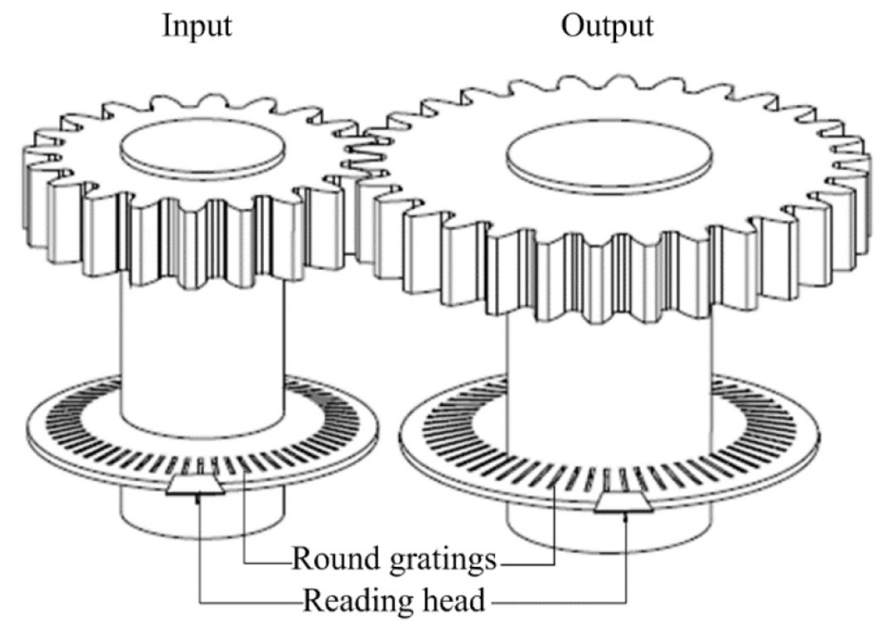

Fig. 3. Transmission error measurement principle.

\subsection{Transmission error measurement principle}

Gear pair transmission error is the difference between the actual angle of the output end of the gear pair and its theoretical angle [21], it is a process of continuous comparison between the actual position and the theoretical position. The displacement synchronization comparison principle is adopted during the measurement process, which is using the angle of one end of the part as a benchmark to examine the difference between the actual position value of the other end and the theoretical value [22]. Gear single flank meshing measurement principle is shown in Figure 3. In order to do single flank meshing rolling with backlash, Gears are installed at the nominal center distance between the input and output shafts. When the input shaft rotary angle is $\theta_{1}(t)$, the theoretical angle of the output shaft is $\theta_{2}(t)$. If the input and output gear teeth are $Z_{1}$ and $Z_{2}$ respectively, $\theta_{2}(t)$ can be expressed as $\theta_{2}(t)=\left(Z_{1} / Z_{2}\right) \theta_{1}(t)$ according to the gear transmission. Assuming the transmission error is $\theta(t)$, in accordance with the definition of transmission error, $\theta(t)$ can be expressed as:

$$
\theta(t)=\theta_{2}(t)-\frac{Z_{1}}{Z_{2}} \theta_{1}(t)
$$

In general measurement, the circular grating is used to acquire the angular displacement information of the driving and driven axis. The accuracy of the grating sensor determines the accuracy of the transmission error measurement results. Considering the effect of eccentricity, the read head and the grating disc should be separated and be installed within a certain extent, which can improve the speed of the measuring process and meet requirements of the practical working conditions. This project adopts Renishaw dual read head split-type grating.

\subsection{Vibration measurement principle}

When measuring vibration by contact, the sensor housing, attached to the vibration surface of the measured object, will vibrate together with the measured object. In the sensor housing, the mass $m$ is connected with the shell through the spring $k$ and the damper $c$. The vibration displacement of the measured surface together with the shell is recorded as $y(t)$, the vibration displacement of the mass $m$ is $x(t)$, and the relative motion between the mass and the shell is $z(t)$, which can also be expressed as $z(t)=x(t)-y(t)$. For the whole vibration measurement system, the following differential equation can be determined using the vibration system theory.

$$
\ddot{z}(t)+2 \xi \omega_{n} \dot{z}(t)+\omega_{n}^{2} z(t)=-\ddot{y}(t)
$$

in which $z(t)$ could be written in oscillation ode, $z(t)=A \cos (\omega t+\varphi) ; \omega_{n}=\sqrt{k / m} ; \xi=c /\left(2 m \omega_{n}\right)$.

When the mass $m$ is small and the stiffness $k$ is relatively large, $\omega_{n}$ will be very large. So the first two terms of the equation (5) compared with the third one can be omitted.

$$
\omega_{n}^{2} z(t)=-\ddot{y}(t)
$$

Thus, in this case, the vibration acceleration measured by the electrical measurement device is proportional to the vibration acceleration of the measured object. Usually in applications, the acceleration sensor is used to acquire the speed of the measured object, and then the vibration displacement of measured object is also known through the integral method. The advantage of this method is that the quality of sensors is relatively small.

The developed gear dynamic performance testing machine of this project belongs to precision measuring and testing device. It has high requirements on the static balance of the shafting. Therefore, when measuring the vibration displacement of the shafting system, it is required that the quality of the vibration sensor used is as small as possible so as not to affect the balance of the shafting. Considering the signal characteristics and mass properties of the displacement sensor and the accelerometer, the three-axis piezoelectric acceleration sensor is used as the transducer element. So, the vibration value of the three directions can be obtained simultaneously through one sensor.

The coordinate system of each component in the driving unit is established as shown in Figure 4 . The absolute coordinate system $S_{r}\left(X_{r}, Y_{r}, Z_{r}\right)$ is established at the position where the center line of the driving unit guide rail intersects with the driven unit guide rail in order to simplify the calculation. The coordinate system $S_{a}\left(X_{a}, Y_{a}, Z_{a}\right)$ of the driving unit box is established at the center of the end face closest to the gear of driving unit box, and the directions are the same as the directions of the absolute coordinate system. At the same time, threeaxis piezoelectric acceleration sensor is fixed according to $S_{a}\left(X_{a}, Y_{a}, Z_{a}\right)$.

According to this method the coordinate system $S_{h}\left(X_{h}, Y_{h}, Z_{h}\right)$ is established on the driving axis; the driving unit fixture coordinate system $S_{s}\left(X_{s}, Y_{s}, Z_{s}\right)$ is established on the fixture end face of the fixture axis; the driving unit gear coordinate system $S_{1}\left(X_{1}, Y_{1}, Z_{1}\right)$ is established at the same point as the active unit fixture coordinate system. 


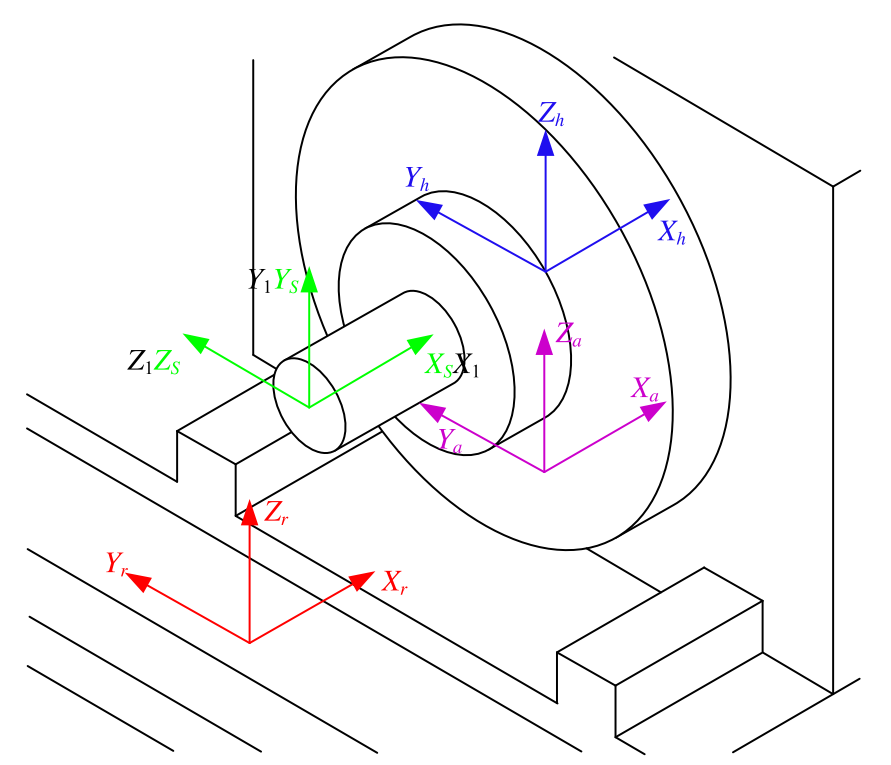

Fig. 4. Coordinate systems of driving unit.

\subsection{Torque measurement principle}

When subjected to torsion, elastic axes are deformed with stress and strain and a shear stress on the cross-section. According to the principle of mechanics of materials, when the external deformation of the axis is pure torsion, the relationship between the cross-section of the shear stress and the shaft torque is shown as equation (7).

$$
\tau=\frac{M}{W_{p}}
$$

$M$ is the torque on the shaft. $W_{p}$ is the torsional modulus of the shaft section. Strain gauges are attached to the elastic axis to form a strain bridge. When the elastic shaft is deformed by the torque, the resistance value of the bridge is changed. After a series of changes, the torque of the elastic axis can be measured. By amplifying the strain signal and conversing the voltage to frequency, the strain signal becomes in proportion to the frequency. At present, the strain sensor technology is the most widely used.

\section{Mechanical system design}

Through a comprehensive survey of the current gear manufacture industry, the instrument's main technical specifications is determined from various types of test items of the precision and reliability requirements, as shown in Table 1.

\subsection{Structure type}

As to whether the power transfer process of a gear tester constitutes a closed system, the gear tester is often divided into two types. One is power flow closed and the other is power flow open [23]. The general structure of the power open tester is shown in Figure 5. When the tester is loaded, all the required power is dissipated during the loading
Table 1. Specifications of gear dynamics machine.

\begin{tabular}{ll}
\hline Items & Requirements \\
\hline Testing object & Spur gear/helical gear \\
Modules & $1-5$ \\
Face width & $0-80 \mathrm{~mm}$ \\
Precision grade & $5-6$ \\
Torque loaded & $0-100 \mathrm{~N} \mathrm{~m}$ \\
Speed & $0-2000 \mathrm{r} / \mathrm{min}$ \\
Lubrication & Controllable \\
Shafting run-out & $\leq 3 \mu \mathrm{m}$ \\
Shafting parallelism & $\leq 3 \mu \mathrm{m}$ \\
Testing function & Static TE, loaded TE, \\
& dynamic TE, vibration, noise, \\
Working temperature & $20 \pm 5^{\circ} \mathrm{C}$ \\
\hline
\end{tabular}

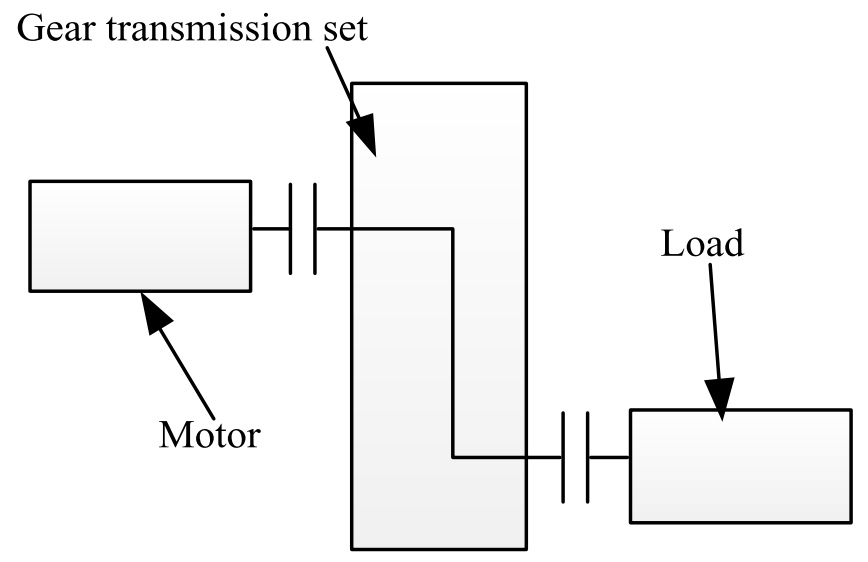

Fig. 5. The test device of power open.

process, and the energy loss is large. Generally, it is only suitable for small power and short time working condition.

Generally, when the designed testing machine is in normal work, the power is about $3 \mathrm{Kw}$ and the test time of single test is less than 5 minutes. So structure type of this machine adopts the flow power open. According to the main technical specifications, related measurement principle and the principles of precision instrument design [24], the basic structure of the testing machine is determined, shown as Figure 6.

In the whole structure, sensors, bearings and guide rails are standard parts, and all the other mechanical structures are newly designed.

\subsection{Loading equipment}

After analysis of the gear tester loading method, there are three ways, such as magnetic brake loading, the electric motor loading and electro-hydraulic servo brake loading. While the electrically controlled motor loading and 


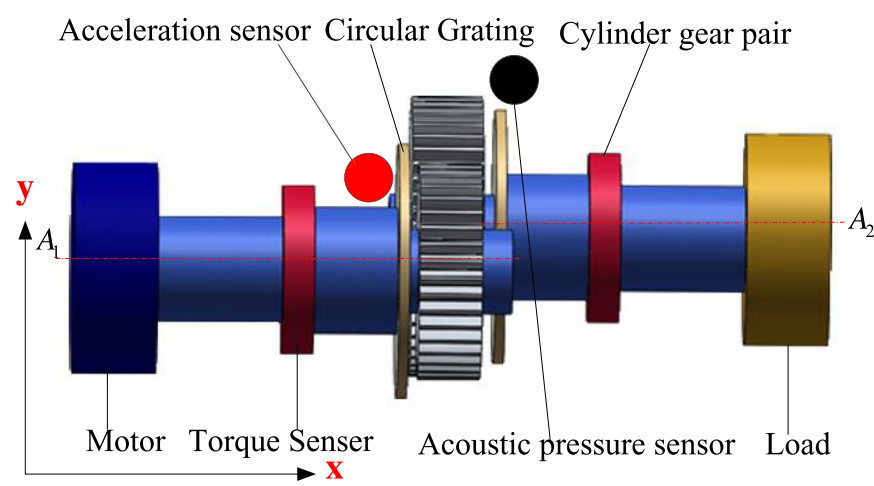

Fig. 6. Structure of the testing machine.

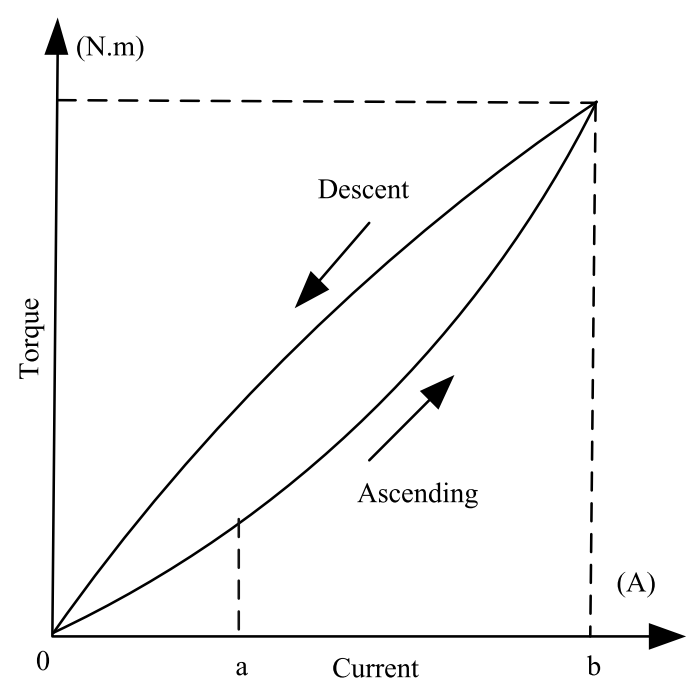

Fig. 7. The relationship between torque and current.

electro-hydraulic servo brake loading are usually applied to larger power occasions, in the low-power loading system, magnetic powder brake loading is universally used. It has the advantages of high performance, low price, fast response, simple structure, no impact, no vibration and no noise. It is mainly used in tension automatic controllable system and in the system for torque, speed and power test. It can also be used in the systems of buffering start, overload protection, adjusting the load, adjusting the speed, and so on. Due to the hysteresis of the magneto resistance, the saturation of the magnetic flux, the nonconstant permeability, the input current and the output torque do not show an approximate linear relationship. When the input current increases linearly and decreases linearly, the actual torque loading characteristic curve is shown in Figure 7.

\subsection{Shaft components}

Precision shafting is one of the important parts of precision machinery. In mechanical design, precision shafting is required to have high rotation precision, enough rigidity, smoothly rotation flexibility and no blocking phenomenon.

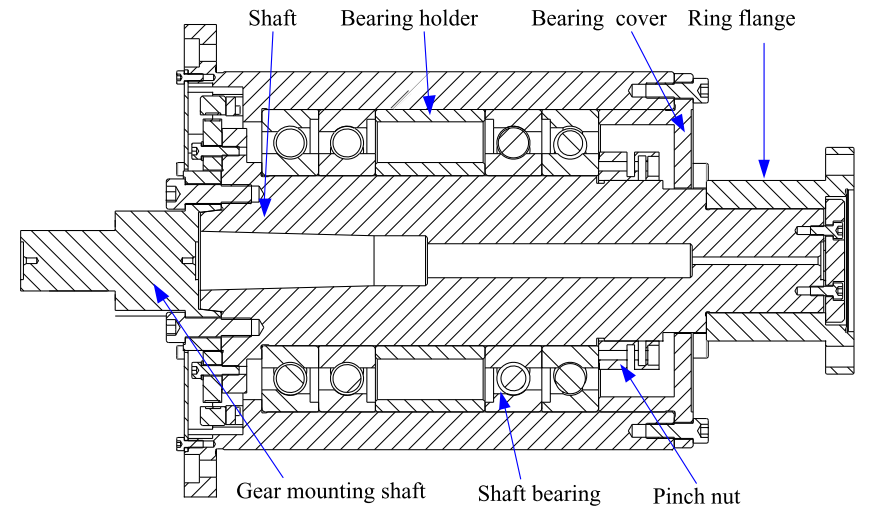

Fig. 8. Precision rotary spindle.

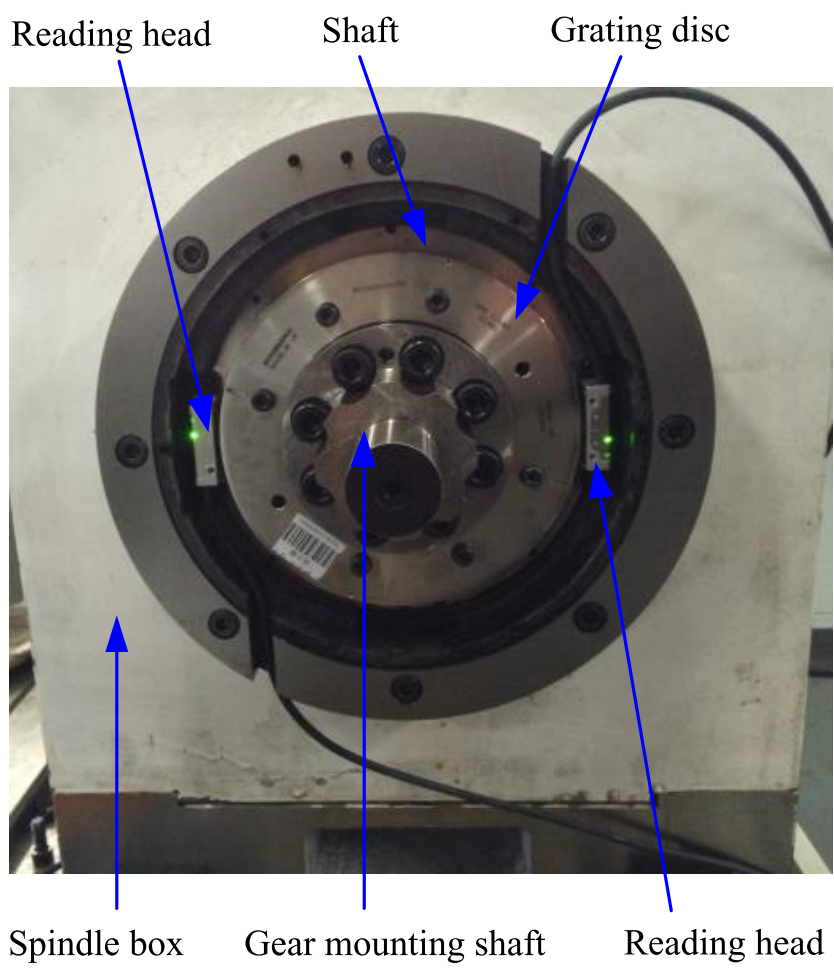

Fig. 9. Grating installation instructions.

According to the precision instrument design criteria and the structure of the electric spindle, the designed precision rotary spindle system structure is shown in Figure 8.

The precision spindle system consists of spindle housing, precision bearings, bushings, lock nuts and other components. The assembled shaft system is installed into the spindle box. Precision shafting and the box are separated not only to improve the accuracy of the spindle but also to reduce the difficulty of processing and assembly. A high accuracy circular grating is used to measure the angular displacement. The double reading heads structure is adopted to reduce the measurement error caused by eccentricity of the shaft. The average value of the output signals of the two reading heads is regarded as the measured value. The installation shown as Figure 9 is 


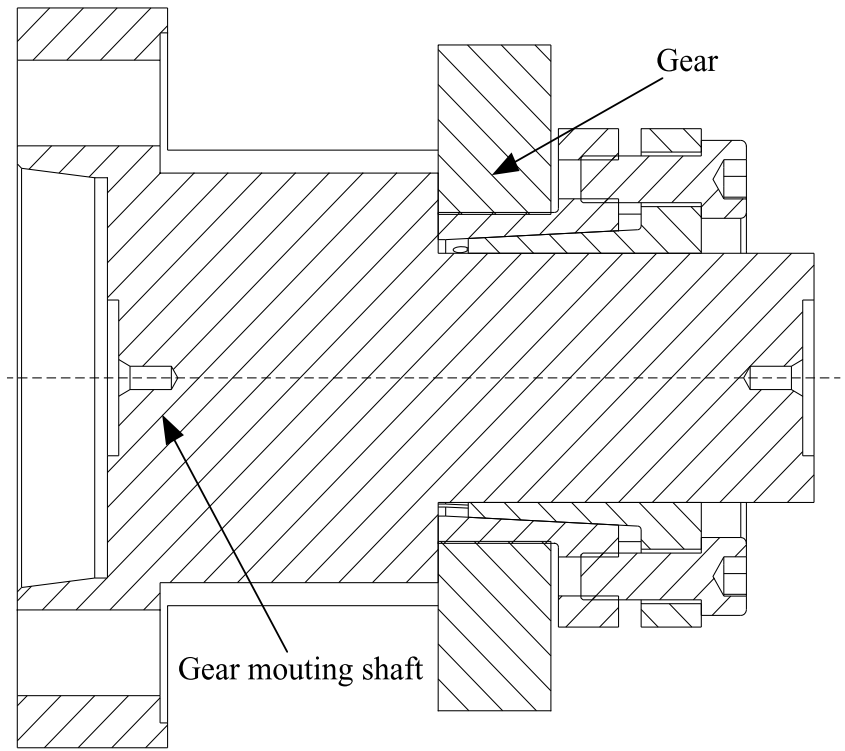

Fig. 10. Gear installation instruction.

in line with "average error principle" in instrument design. The method of repeating measurement and averaging can improve the accuracy of the instrument.

\subsection{Gear mounting device}

To be suitable for different tested gears, the spindle used to mount the gear is designed to be selected and replaced according to the size of the gear. So the concentricity of the spindle and the precision shafting is the key factor affecting the performance of the instrument. With reference to the design principle of the machine tool spindle standard interface, the connection between the spindle and the precision shafting is in the form of a short taper shaft. The orientation and centering of the short cone can be a good guarantee of concentric accuracy. Bolted connection can be used to ensure the flexibility of assembly and adjustment of the shaft system accuracy. The expansion of the gear affects the convenience of the test and the accuracy of the shaft. Especially, in the loaded condition, the size of the tightening force seriously limits the accuracy and reliability of the transmission error measurement. Considering the principle of simple operation and precise control, the designed gear mounting device is shown in Figure 10.

\subsection{Measuring machine constitution}

The testing machine is mainly composed of bottom base, precision rotary shaft, active shafting box, passive shafting box, mobile platform, measuring system and so on. Its structure is shown in Figure 11. The base is made of cast iron. In order to ensure the smoothness of the movement of the box, the flat rail and the moving platform are driven in combination by the ball screw. The measuring system is mainly composed of round grating, torque sensor, magnetic powder brake to complete the gear dynamic performance test on the testing machine.

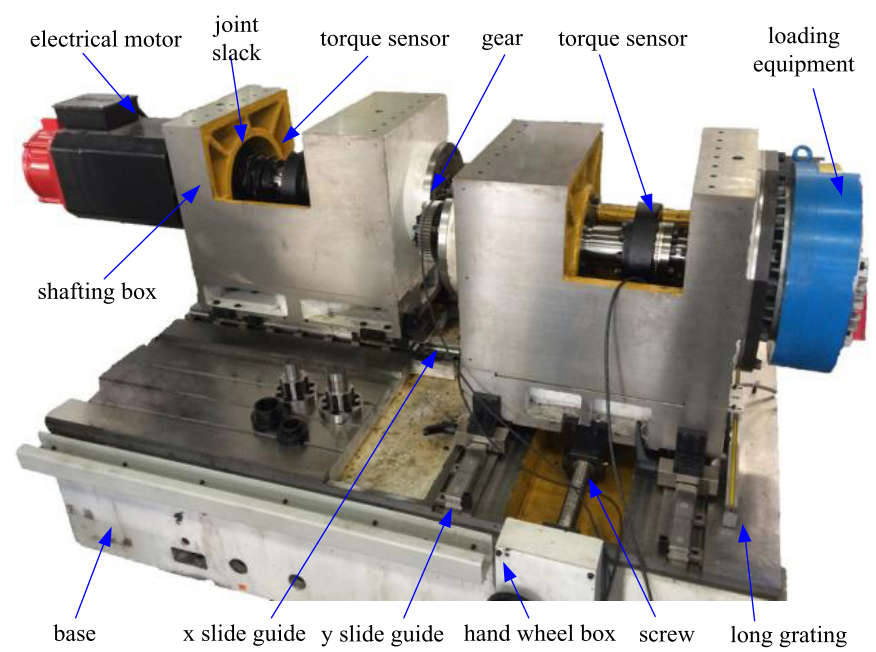

Fig. 11. Mechanical structure of testing machine.

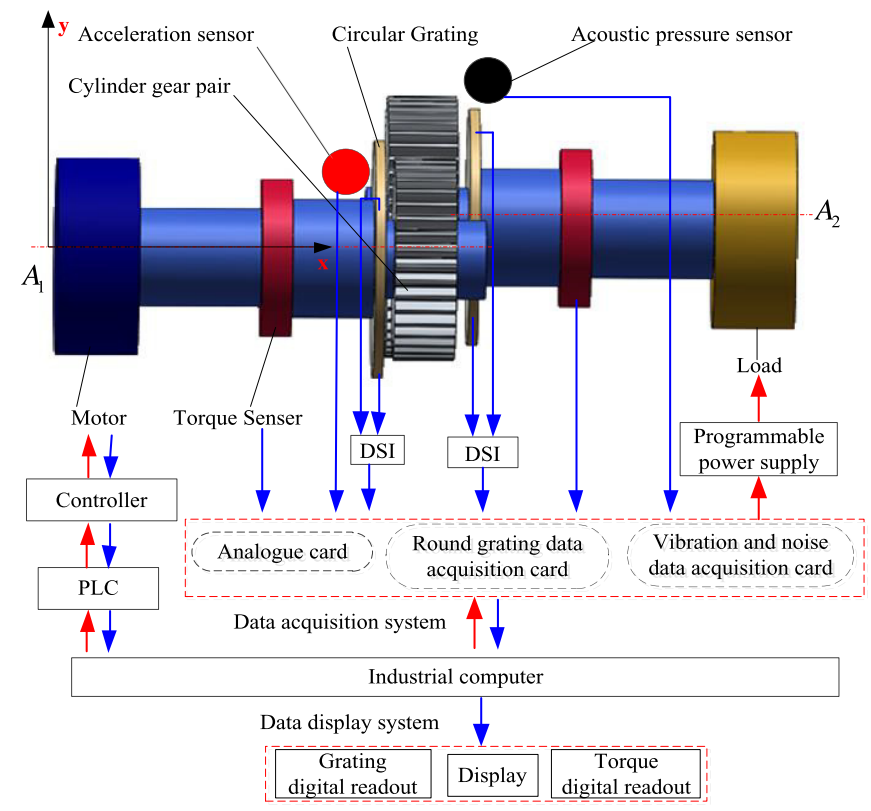

Fig. 12. Testing machine control system.

\section{Testing machine measurement and control system}

\subsection{Principle of measurement and control}

The testing machine control system hardware is mainly composed of the data collection system and data display system. The motor is controlled through the PLC. The data acquisition system comprises circular grating sensors, subdivision devices, DSI cards, torque moment sensors, vibration sensors, noise sensors, data acquisition cards and the industrial computer. The data display system comprises a grating display, a torque display and a display of the industrial computer. The structure is shown in Figure 12. 


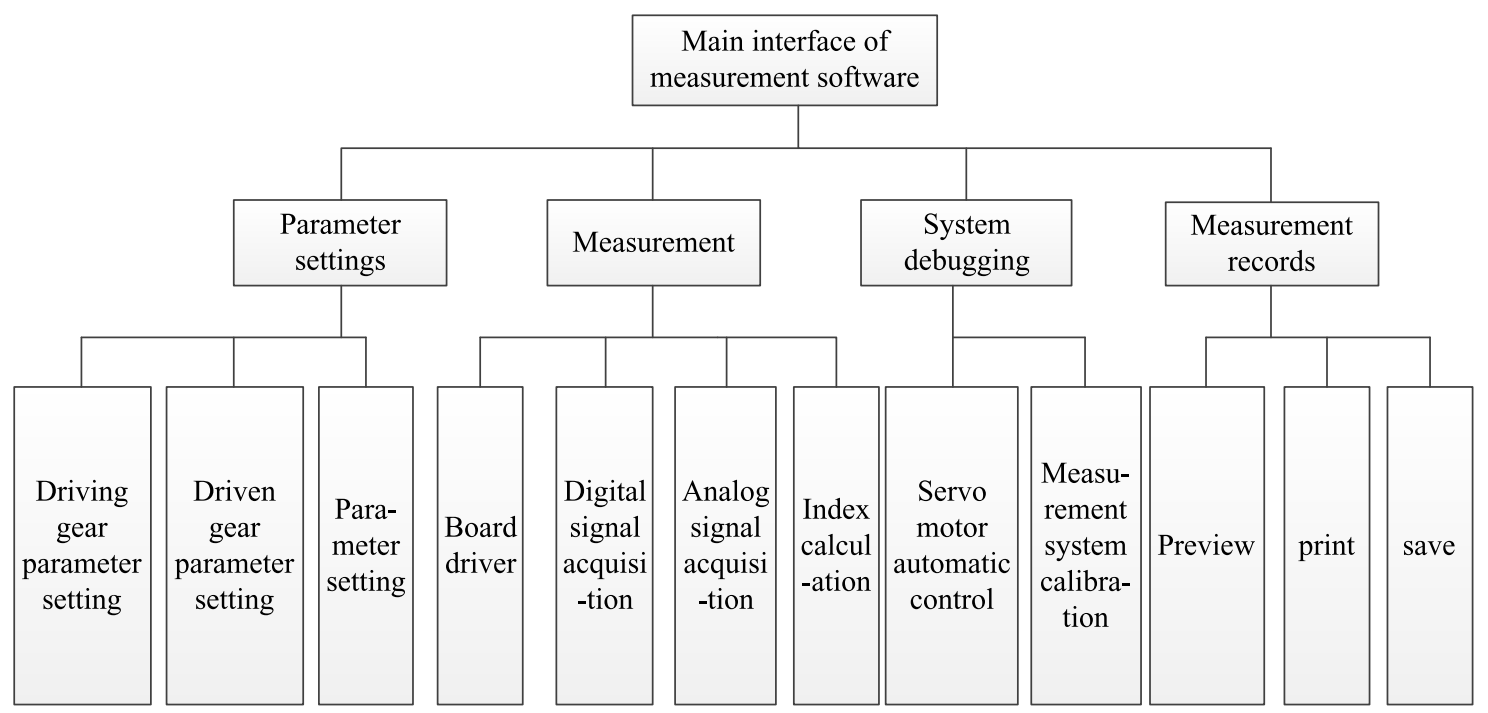

Fig. 13. Software architecture.

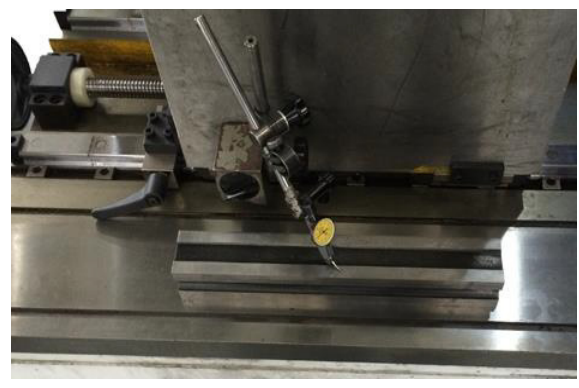

(a)

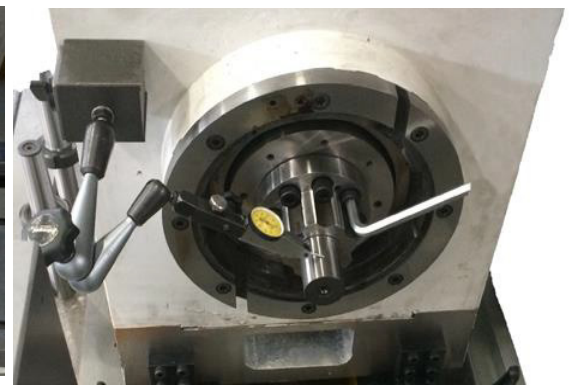

(b)

Fig. 14. Testing machine precision of detection. (a) Parallelism detection. (b) Run-out detection.

In order to realize the automatic measurement of gear dynamic performance (static transmission error, dynamic transmission error, vibration and noise, etc.), the test system mainly consists of driving device, tested gear pair, loading device and detection device. The motor acts as a drive unit for the whole testing machine, providing power to the tester. The power is transmitted to the loading device (magnetic powder brake) through the detection device (various sensor devices) and gears.

The control unit of the motor uses the control structure of combining PLC and servo drive with the speed closedloop mode. The programmable power supply is used to control the magnetic powder brake by the current control mode. The round grating signal is collected by the data collecting card of the Contac. The vibration and noise signals are collected by the vibration and noise data acquisition system, and the synchronization between the various cards is carried out by using the round grating data acquisition card to send the triggering signal. When the tester is offline, it can be used as a gear rotation platform.
After entering the testing machine monitoring and control system, the external button will be unavailable and the test and control software will be used to carry out the test.

\subsection{Software system}

Software is developed in $\mathrm{VC}++$ which is the most popular Windows platform application development environment. The software system is divided into parameter management module, measurement on-site control module, comprehensive performance analysis module and user management function modules, as shown in Figure 13.

\section{Precision analysis and testing}

The accuracy of the testing machine is mainly affected by mechanical system error, standard error and signal processing and algorithm error. The spindle run-out and installation eccentric is tested by using the dial gauge and standard unit, as shown in Figure 14. 
Table 2. Specifications of gear dynamics machine.

\begin{tabular}{llll}
\hline Error items & References & Error & Uncertainty \\
\hline Input axis radial runout & $3 \mu \mathrm{m}$ & $2.3 \mu \mathrm{m}$ & $1.63 \mu \mathrm{m}$ \\
Output axis radial runout & $3 \mu \mathrm{m}$ & $2.8 \mu \mathrm{m}$ & $1.98 \mu \mathrm{m}$ \\
Input axis axial runout & $3 \mu \mathrm{m}$ & $2.2 \mu \mathrm{m}$ & $0.11 \mu \mathrm{m}$ \\
Output axis axial runout & $3 \mu \mathrm{m}$ & $2.5 \mu \mathrm{m}$ & $0.13 \mu \mathrm{m}$ \\
Input axis eccentricity & $3 \mu \mathrm{m}$ & $1.8 \mu \mathrm{m}$ & $1.23 \mu \mathrm{m}$ \\
Output axis eccentricity & $3 \mu \mathrm{m}$ & $2.3 \mu \mathrm{m}$ & $1.67 \mu \mathrm{m}$ \\
Accuracy of circular grating & $3.2^{\prime \prime}$ & $3.2^{\prime \prime}$ & $0.89 \mu \mathrm{m}$ \\
Accuracy of circular grating & $3.2^{\prime \prime}$ & $3.2^{\prime \prime}$ & $0.89 \mu \mathrm{m}$ \\
Sub-division & $1.62^{\prime \prime}$ & $1.62^{\prime \prime}$ & $0.08 \mu \mathrm{m}$ \\
Electrical system stability & $0.5^{\prime \prime}$ & $0.35^{\prime \prime}$ & $0.25 \mu \mathrm{m}$ \\
Algorithm error & $0.005 \mu \mathrm{m}$ & $0.005 \mu \mathrm{m}$ & $0.003 \mu \mathrm{m}$ \\
\hline
\end{tabular}

The detection accuracy indexes, grating accuracy and software and electrical indicators are acquired by comprehensive testing, as shown in Table 2. The influencing factors are independent of each other, and the correlation coefficient is zero. Therefore, the influence on the total deviation of tangential synthesis is:

$$
\Delta F^{\prime}{ }_{i}= \pm \sum_{i=1}^{11} \sqrt{\Delta_{i}^{2}}= \pm 3.54 \mu \mathrm{m}
$$

The allowable value of the total deviation of the tangential integration of the 5-class accuracy (indexing diameter $200 \mathrm{~mm}$, modulus 2.5 , and pressure angle $20^{\circ}$ ) is $30 \mu \mathrm{m}$. The measured error is less than $1 / 3(10 \mu \mathrm{m})$ of the total allowable tangential total deviation. So the testing machine can meet the requirements of five precision gear measurements.

\section{Analysis of the test results}

A series of measurement tests are carried out on the gear dynamics testing machine. The parameters of a pair of gears are shown in Table 3, the tooth profile deviation values are shown in Table 4, and the test condition parameters are shown in Table 5 . The measured transmission error curves are shown in Figure 15. The gear pair working center distance is $153.14 \mathrm{~mm}$, and the transmission ratio is 1.47 .

Three-axis piezoelectric acceleration sensor is fixed with the screw on the front end of the bearing seat near the gear. The acceleration signal of the gear vibration is obtained through the vibration data acquisition system. When the test speed is $10 \mathrm{r} / \mathrm{min}$, the signals of the acceleration of the driving gear in the $x, y$ and $z$ directions are shown in Figure 16.

The time-domain statistical index of the vibration signal can be used to judge the operation state of the equipment, such as hidden trouble, the extent and the development trend of the trouble. Major statistical indicators used are average value, root-mean-square quantity, peak value pulse value margin value and kurtosis value.
Table 3. The gear basic parameters.

\begin{tabular}{lll}
\hline Items & Gear 1 & Gear 2 \\
\hline Tooth number $/ z$ & 38 & 56 \\
Module $/ m$ & 2.25 & 2.25 \\
Helical angle $/ \beta$ & 0 & 0 \\
Pressure angle $/ \alpha$ & 20 & 20 \\
Face width $/ b$ & 25 & 30 \\
Variation Coefficient $/ x$ & 0 & 0 \\
\hline
\end{tabular}

Table 4. Gear tooth profile deviation.

\begin{tabular}{lllll}
\hline No. & $f p t(\mu \mathrm{m})$ & $R p(\mu \mathrm{m})$ & $F p(\mu \mathrm{m})$ & $Q$ \\
\hline 1 & 4.6 & 22 & 18.5 & 5 \\
2 & 1.8 & 0.7 & 26.2 & 5 \\
\hline
\end{tabular}

Table 5. Test conditions parameters

\begin{tabular}{lll}
\hline Speed $(\mathrm{r} / \mathrm{min})$ & Torque $(\mathrm{Nm})$ & Lubrication \\
\hline 10 & 0 & no \\
30 & 0 & no \\
60 & 0 & no \\
90 & 0 & no \\
\hline
\end{tabular}

In this paper, the average value, square value and kurtosis value are selected as the evaluation index for the operation condition of gear testing machine.

The average value $\bar{X}$ is the first order moment statistical average of the signal and is used to describe the stable component of the signal, which is the equilibrium position of the mechanical vibration.

$$
\bar{X}=\frac{1}{N} \sum_{i=1}^{N} x_{i}(t)
$$




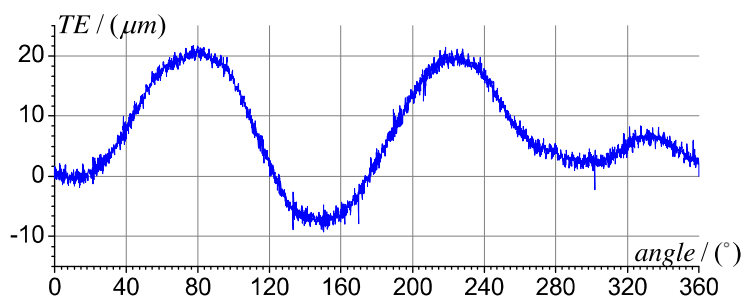

(a)

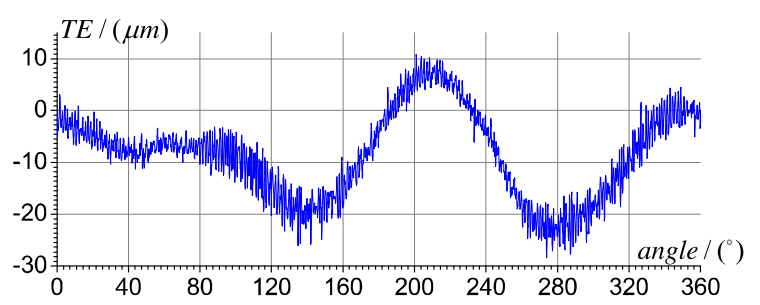

(c)

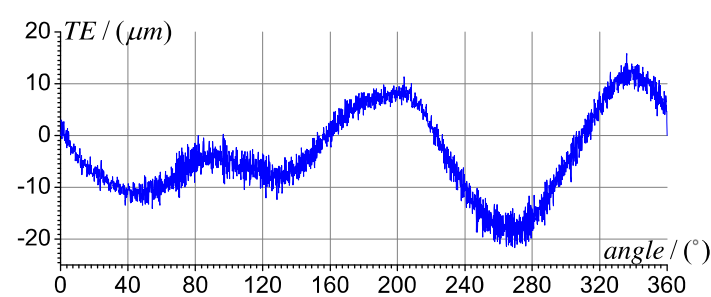

(b)

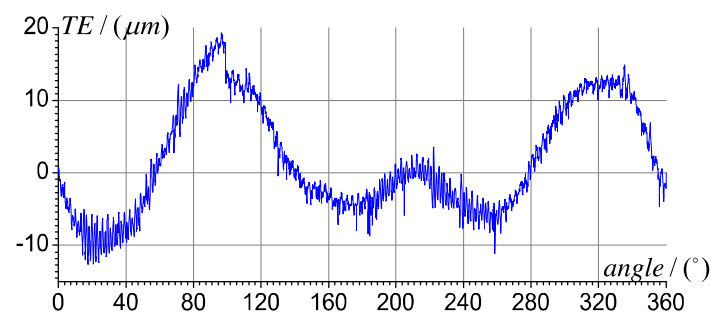

(d)

Fig. 15. Gear transmission error curve. (a) TE at $10 \mathrm{r} / \mathrm{min}$ (b) TE at $30 \mathrm{r} / \mathrm{min}$ (c) TE at $60 \mathrm{r} / \mathrm{min}$ (d) $\mathrm{TE}$ at $90 \mathrm{r} / \mathrm{min}$.

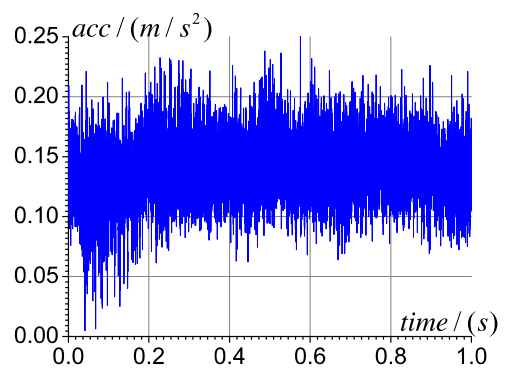

(a)

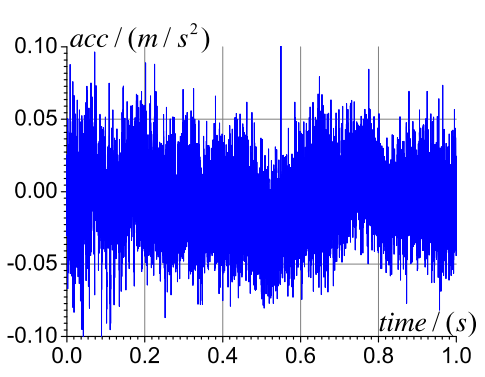

(b)

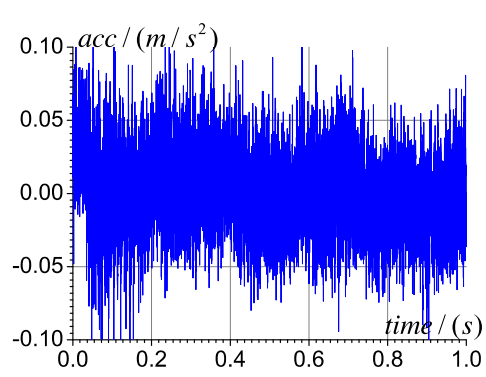

(c)

Fig. 16. Acceleration curve at $n=10 \mathrm{r} / \mathrm{min}$. (a) $\mathrm{n}=10 \mathrm{r} / \mathrm{min}, \mathrm{x} \operatorname{direction}(\mathrm{b}) \mathrm{n}=10 \mathrm{r} / \mathrm{min}, \mathrm{y}$ direction $(\mathrm{c}) \mathrm{n}=10 \mathrm{r} / \mathrm{min}, \mathrm{z} \operatorname{direction}$.

Square value is the second order moment statistical average of the signal, and root-mean-square quantity is used to describe the vibration signal energy, which is often used to determine whether the state of operation is normal.

$$
X_{r m s}^{2}=\frac{1}{N} \sum_{i=1}^{N} x_{i}^{2}(t)
$$

$X_{r m s}$ is root-mean-square quantity. Kurtosis $C_{q}$ is the fourth-order moment average of the signal, which is often used to characterize the impact vibration of the mechanical during the operation. The characteristic of index is sensitive. Normally the value is 3 . If the value is close to 4 or more than 4 , it means that there is impact vibration during working. Generally speaking, the reason is that the gap is too large, or the sliding surface is broken.

$$
C_{q}=\frac{\frac{1}{N} \sum\left(\left|x_{i}\right|-\bar{x}\right)^{4}}{X_{r m s}^{4}}
$$

Table 6. Vibration acceleration signal statistical indicators.

\begin{tabular}{llll}
\hline & $x$ & $y$ & $z$ \\
\hline Average value & -0.01074 & -0.03292 & 0.01819 \\
Square value & 0.03448 & 0.02481 & 0.11403 \\
Kurtosis value & 0.00277 & 0.00097 & 0.02518 \\
\hline
\end{tabular}

According to the equations (9) to (11), the statistical analysis of the obtained signal is shown in Table 6 . Among the indicators in the table, the mean value of the average value of the vibration signal is 0.0206 , the mean square value is 0.0577 , and the average kurtosis is 0.0096 . Therefore, it can be shown that the shaft of the gear testing machine is stable, the vibration signal is very small and the disturbance of vibration energy is very small. So there is no obvious impact during gear in normal meshing operation. 


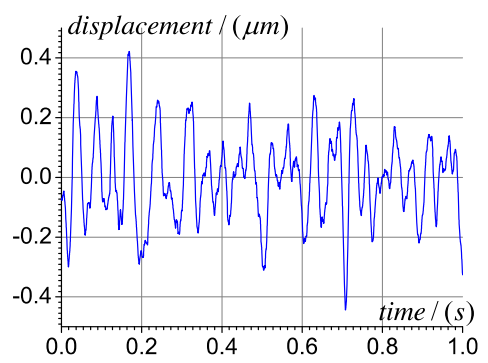

(a)

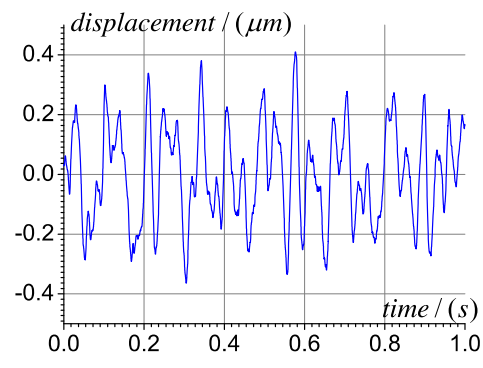

(b)

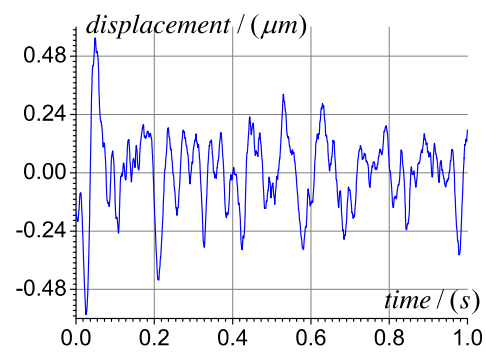

(c)

Fig. 17. Displacement curve of time domain. (a) $\mathrm{n}=10 \mathrm{r} / \mathrm{min}, \mathrm{x}$ direction (b) $\mathrm{n}=10 \mathrm{r} / \mathrm{min}, \mathrm{y}$ direction $(\mathrm{c}) \mathrm{n}=10 \mathrm{r} / \mathrm{min}, \mathrm{z}$ direction.

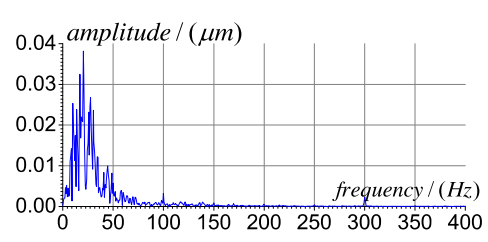

(a)

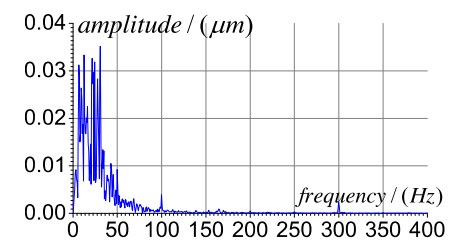

(b)

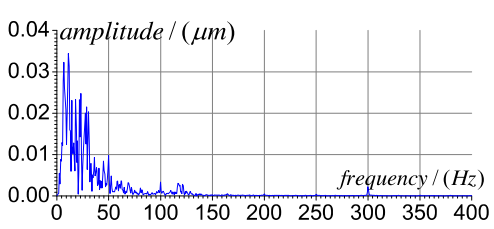

(c)

Fig. 18. Displacement curve of frequency domain. (a) $\mathrm{n}=10 \mathrm{r} / \mathrm{min}, \mathrm{x}$ direction (b) $\mathrm{n}=10 \mathrm{r} / \mathrm{min}, \mathrm{y} \operatorname{direction}(\mathrm{c}) \mathrm{n}=10 \mathrm{r} / \mathrm{min}$, $\mathrm{z}$ direction.

From the acceleration signal of the vibration, we cannot see a significant amount of vibration displacement. So, it is unobvious whether the disturbance caused by vibration affect the normal detection. Therefore, using the numerical integration method of discrete points, the acceleration signal of vibration can be integrated twice and the vibration displacement signal can be obtained. The vibration displacement signals in the three directions are shown in Figure 17, which are integrated by using the equation (12). The integral formula shows that the integral of the discrete vibration signal can be the vibration displacement signal.

$$
y(k)=\Delta t \sum_{i=1}^{k} \frac{x(i-1)+x(i)}{2}(k=1,2,3, \cdots, N)
$$

From Figure 17, it can be seen that the maximum value of vibration displacement is less than $0.6 \mu \mathrm{m}$, while the measured total deviation of the tangential direction of the gear is $30 \mu \mathrm{m}$, so the effect of vibration on the measurement result is relatively small. The signal is shown as a cycle signal, which is similar to the process of gear meshing. Further, the time domain signal is transformed into a frequency domain signal by using a spectrum analysis technique, as shown in Figure 18.

In Figure 18, each frequency component of the signal has a sharp peak at $50 \mathrm{~Hz}$ or less, and the amplitude of vibration is particularly obvious near $20 \mathrm{~Hz}$. In the gear dynamic test system, the gear meshing is the major excitation source of the external vibration. When the measuring speed is $10 \mathrm{r} / \mathrm{min}$, the corresponding shaft rotation frequency is $0.17 \mathrm{~Hz}$ and the meshing frequency is $9 \mathrm{~Hz}$. So the testing process can be good to avoid the resonance effect caused by the external excitation.
As the measurement speed increases and the number of gear teeth increases, the external excitation frequency may cause the resonance of the system. So it is needed to use a reasonable speed to avoid the impact of resonance.

In order to analyze the influence of rotational speed on the measurement results, the displacement curves of the vibration signals are shown in Figure 19 at the speed of 30 , 60, 90 and 120. In Figure 19, it can be seen that the maximum displacement of the vibration under various rotational speeds is all below $0.6 \mu \mathrm{m}$, which can meet the evaluation requirement of the test result.

\section{Conclusions}

- From the previous analysis, the developed gear dynamic performance testing machine based on the gear dynamics principle can meet the requirements of gear dynamic experiments, such as static transmission error, dynamic transmission error, vibration and noise. This provides new equipment for gear test.

- Through the analysis of the accuracy of the machine, the uncertainty is $3.54 \mu \mathrm{m}$, which can meet the requirements of 5-6 gear dynamic test.

- The vibration amplitude of the shaft system is below $0.6 \mu \mathrm{m}$ during the testing, which will not affect the accuracy of test results. The increase of rotational speed does not cause the increase of vibration displacement, which indicates that the machine has good anti-vibration performance.

- The testing machine's low-order resonance frequency is in the vicinity of $20 \mathrm{~Hz}$. During the normal working speed detection, the tester resonance will not happen. By selecting and detecting the rotational speed, it is possible to improve the dynamic accuracy. 


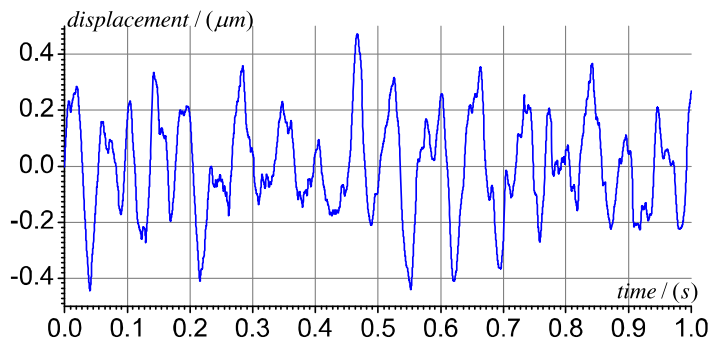

(a)

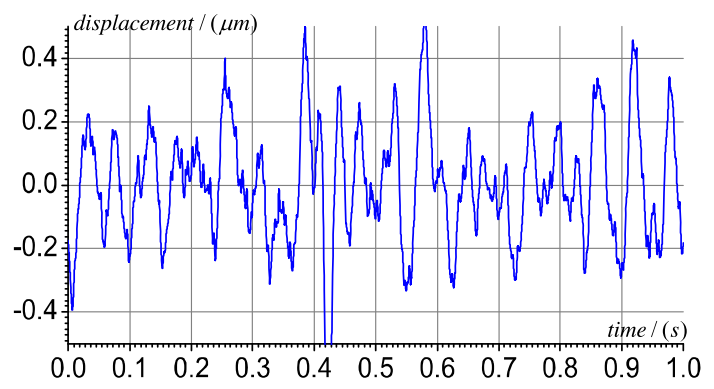

(c)

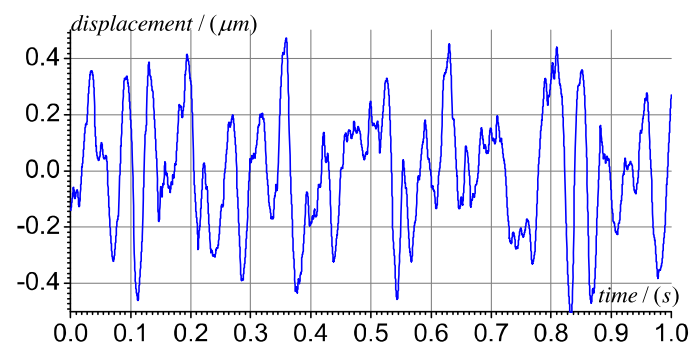

(b)

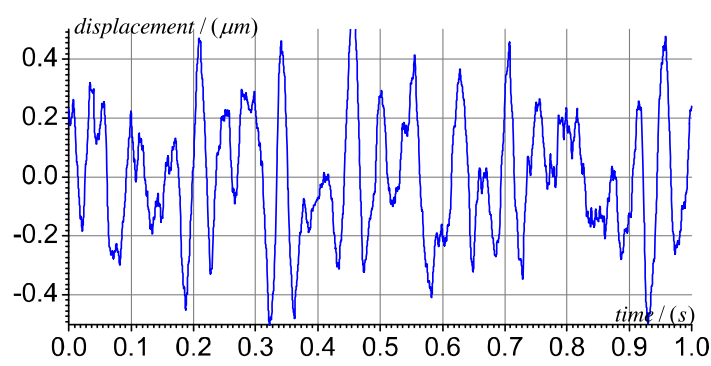

(d)

Fig. 19. Vibration displacement curves at different speeds. (a) $n=30 \mathrm{r} / \mathrm{min}, \mathrm{x} \operatorname{direction}(\mathrm{b}) \mathrm{n}=60 \mathrm{r} / \mathrm{min}, \mathrm{x} \operatorname{direction}(\mathrm{c}) \mathrm{n}=90 \mathrm{r} / \mathrm{min}$, $\mathrm{x}$ direction $(\mathrm{d}) \mathrm{n}=120 \mathrm{r} / \mathrm{min}$, $\mathrm{x}$ direction.

This work is supported by the Natural Science Foundation of China (No. 51635001).

\section{References}

1. J. Zhang, L. Ji, Z.Y. Huang, P.P. Zhang, W. Wang, A simple estimation of coupling loss factors for two flexible subsystems connected via discrete interfaces, Shock Vibr. 2016, 3636401-1 (2016)

2. X. Liao, J.R. Zhang, X.Y. Xu, Analytical model of bolted joint structure and its nonlinear dynamic characteristics in transient excitation, Shock Vibr. PT. 7, 1-11 (2016)

3. F. Hartig, H. Lin, K. Kniel, Z.Y. Shi, Standard conforming involute gear metrology using an articulated arm coordinate measuring system, Measur. Sci. Technol. 45, 105011 (2012)

4. C. Wang, H.Y. Cui, Q.P. Zhang, W.M. Wang, Modified optimization and experimental investigation of transmission error, vibration and noise for double helical gears, J. Vib. Control 2014, 1-13 (2014)

5. Z.Y. Shi, Y.T. Fei, H.K. Xie, Gear measurement technology in 100 year-retrospect and prospect, Eng. Sci. 9, 17-21 (2003)

6. J.L. Xu, L. Wan, W.X. Luo, Influence of bearing stiffness on the nonlinear dynamics of a shaft-final drive system, Shock Vibr. 2016, 3524609 (2016)

7. Z.H. Shu, Z.Y. Shi, H.F. Chen, J.C. Lin, Y. Kang, Research on gear integrated error curves, International Gear Conference (2014)

8. L. Hong, Y.Z. Qu, Y.G. Tan, M.Y. Liu, Z.D. Zhou, Vibration based diagnosis for planetary gearboxes using an analytical model, Shock Vibr. 2016, 2620518 (2016)

9. J.M. Yang, P. Yang, Random vibration and dynamic analysis of a planetary gear train in a wind turbine, Shock Vibr. 8, 1-10 (2016)

10. H.F. Chen, Y.Q. Sun, Z.Y. Shi, J.C. Lin, Intelligent analysis method of gear faults based on FRWT and SVM, Shock Vibr. 2016, 1582738 (2016)
11. Z.H. Shu, Z.Y. Shi, X.Y. Wang, F.Y. He, H.F. Chen, Development of pairing performance tester for vehicles cylindrical gears, ASME 2015 International Design Engineering Technical Conferences and Computers and Information in Engineering Conference (2015)

12. Z.Y. Shi, X.Y. Wang, Z.H. Shu, Theoretical method for calculating the unit curve of gear integrated error, J. Mech. Des. 138, 033301 (2016)

13. J. Tang, Z.Y. Shi, Z.Q. Fang, Novel measurement principle of profile deviations evaluated through double-flank rolling test with rack probe, Proc. SPIE (2012)

14. Z.H. Hu, J.Y. Tang, J. Zhong, S.Y. Chen, Frequency spectrum and vibration analysis of high speed gearrotor system with tooth root crack considering transmission error excitation, Eng. Failure Anal. 60, 405 (2016)

15. Z. Li, S. Liu, R.P. Zhu, X.D. Xu, Investigations of dynamic behaviors of face gear drives associated with pinion dedendum fatigue cracks, Shock Vibr. 2016, 3173860 (2016)

16. A. Romero, Y. Lage, S. Soua, B. Wang, T.H. Gan, Vestas V90-3MW wind turbine gearbox health assessment using a vibration-based condition monitoring system, Shock Vibr. 2016, 6423587 (2016)

17. E.J. Diehl, J. Tang, Predictive modeling of a two-stage gearbox towards fault detection, Shock Vibr. 2016, 9638325 (2016)

18. A. Fernández, M. Iglesias, A. De-Juan, P. García, R. Sancibrián, F. Viadero, Gear transmission dynamic: effects of tooth profile deviations and support flexibility, Appl. Acoust. 77, 138-149 (2014)

19. P. Velex, M. Chapron, H. Fakhfakh, J. Bruyere, S. Becquerelle, On transmission errors and profile modifications minimising dynamic tooth loads in multi-mesh gears, J. Sound Vibr. 379, 28-52 (2016)

20. R.F. Li, J.J. Wang, Dynamics of Gear Systems: Vibration, Shock and Noise, Science Press, Beijing (1997) 
21. R.E. Smith, The uses and limitations of transmission error, Gear Technol. 5, 34-39 (1988)

22. R.G. Munro, A review of the single flank method for testing gears, Ann. CIRP 325-329 (1979)
23. X.Y. Wang, Z.Y. Shi, Z.H. Shu, S. Fu, Study on evaluation system of gear accuracy based on statistical analysis, International Gear Conference (2014)

24. A.H. Slocum, Precision Machine Design, Society of Manufacturing Engineers, Dearborn, MI (1992)

Cite this article as: Ke Li, Bo Yu, Zhaoyao Shi, Zanhui Shu, Rui Li, Development of gear dynamic performance testing machine, Int. J. Metrol. Qual. Eng. 12, 20 (2021) 